\title{
Prevalence of Postural Dysfunction among Female College Students-A Qualitative Analysis
}

\author{
S. Kiruthika ${ }^{1}$, K. Rekha ${ }^{2}$, G. Preethy ${ }^{3 *}$, Manoj Abraham ${ }^{3}$ \\ ${ }^{1}$ Department of Neurology, Saveetha College of Physiotherapy, Saveetha University, Chennai, India \\ ${ }^{2}$ Department of Cardio Pulmonary, Saveetha College of Physiotherapy, Saveetha University, Chennai, India. \\ ${ }^{3}$ Saveetha College of Physiotherapy, Saveetha University, Chennai, India \\ *Corresponding author: Preethy G, Saveetha College of Physiotherapy, Saveetha University, Chennai, India, Tel: 044-66726630; E-mail: preethyg06031996@gmail.com \\ Received: July 07, 2017; Accepted: November 12, 2017; Published: December 18, 2017 \\ Copyright: ( 2017 Kiruthika et al. This is an open-access article distributed under the terms of the Creative Commons Attribution License, which permits unrestricted use, \\ distribution, and reproduction in any medium, provided the original author and source are credited.

Abstract
In the present day, proper posture is considered to be a state of musculoskeletal balance involving minimal body
stress or strain. Modern life and the rise in a sedentary lifestyle have had a negative effect on most of the human motor
behavior. This study included 804 female subjects, who were photographed in the sagittal and frontal planes. The
common postural misalignments analyzed were swayback, lumbar lordosis, thoracic kyphosis, forward head, rounded
shoulder, and pronated foot. The results showed that older women had greater incidence of forward head, thoracic
kyphosis, and pronated foot. The abnormalities were probably related to prolonged sitting and reduced flexibility.

Keywords: Postural dysfunction; Females; Prolonged sitting; Postural abnormalities

\section{Introduction}

Proper postural alignment when sitting and standing allows efficient work with minimal fatigue and strain on body ligaments and muscles. A proper posture is thought to be a state of musculoskeletal balance involving minimal amount of stress or strain to the body. Modern life has negatively affected much of human motor behavior due to an increasing propensity to a sedentary lifestyle [1-3].

Television, video games, motorized transportation, fast food, and lack of regular physical activity all contribute to poor physical condition, leading to anatomical and biomechanical modification in body alignment $[4,5]$.

According to Latalski et al. [4], "Posture" is a motor habit shaped on a specific morphological and functional background. Therefore, posture indicates mechanical efficacy of the kinetic sense as well as muscular balance and neuromuscular coordination. Any change in this can result in altered or bad posture. Postural dysfunction or "poor" posture is characterized by a spine positioned unnaturally, in which the curves are emphasized. This results in stress in the joints, muscles, and vertebrae. Prolonged poor positioning results in a pressure buildup in the surrounding structures.

Common risk factors for postural dysfunctions are lack of knowledge of correct posture, sedentary lifestyle, occupational demands, joint stiffness, decreased fitness, muscle weakness, poor core stability, and poor ergonomic workstations. Bad posture, if not corrected, results in depression, stress, issues with digestion, poor breathing, back pain, and tension headaches. The most common areas of pain are lower back (63\%), neck (53\%), shoulders (38\%), and wrists (33\%). Poor posture can impede the ability of the lungs to expand [6-8].

According to Meckenzie's concept, postural dysfunction can be classified into three major types: postural, dysfunction, and derangement. A postural syndrome is the result of fixed postures or positions for prolonged periods that can affect the joint surfaces, muscles, or tendons. Pain may be local and reproducible when end range positions, such as slouching, are maintained for sustained periods of time. This syndrome in adults and children can be easily corrected with postural correction exercises and by improving the quality of life. Rehabilitation prognosis in the other two categories, dysfunction and derangement syndromes, is poor [11].

Staying in the same position for prolonged periods can result in tightening of the agonist muscles and weakening of the antagonist muscles; hence posture appears cramped. Consequences of these imbalances are forward head posture, thoracic kyphosis, pronated foot, excessive pelvic tilt, rounded shoulder, and so on.

The long-term effect of prolonged sitting while watching or playing games and using phones and computers has been detected as a significant risk factor of altered posture alignment $[9,10]$. The most frequent deviations observed in youngsters are scoliosis, kyphosis, and lordosis. Hence, there is a need for assessing postural alignment for early correction and preventing deterioration.

There are several studies on postural abnormalities among schoolchildren and the elderly. But only a few studies deal with college students, so this study aims to determine the prevalence of postural problems among female college students.

\section{Aim}

This study aims to determine the prevalence of postural dysfunction in the sagittal and frontal planes among female college students.

\section{Materials and Methods}

\section{Sample}

This was an observational study conducted from January to March 2017 on approval from the institutional scientific review board (ISRB). Informed consent was obtained from all participants after due explanation.

The study included 900 nonmedical female students of age range 19-24 years; of which 804 students were recruited depending on 
inclusion and exclusion criteria. The mean age group was 23 years. All students were analyzed by a trained physiotherapist. We excluded those with recent history of fracture and cognitive impairment.

\section{Procedure}

Of the 900 participants, 804 nonmedical female students were inquired about sitting habits and leisure time habits. Postural assessment was based on observation of the students in the sagittal and frontal plane.

The reference points were marked out on each student's image, and the therapist observed and analyzed the posture from both the sagittal and frontal planes $10 \mathrm{~cm}$ away. The reference points were marked using a skin marker, and it included lateral malleolus, anterior superior and posterior superior iliac spines and cervical (C5 and C7) vertebrae.

Each participant was observed for forward head posture, thoracic kyphosis, swayback, exaggerated lumbar lordosis, and hyperextended knee in the sagittal plane. Ankle position (pronation or supination) and head alignment were observed in the frontal plane. After postural assessment, the participants with poor posture were taught posture correction exercises and stretching exercises as a home program. [11]

Postural assessment was based on students' photographs taken in orthostatic posture.

\section{Results}

Descriptive statistical analysis was performed (percentages, mean, and standard deviations). Evaluation of posture lasted approximately $15 \mathrm{~min}$; posture was analyzed in two different planes.

\begin{tabular}{|c|c|c|c|c|}
\hline \multirow{2}{*}{ Age } & \multirow{2}{*}{$\begin{array}{c}\text { Number of } \\
\text { students }\end{array}$} & Height & BMI & Weight \\
\cline { 3 - 5 } & Mean \pm SD & Mean \pm SD & Mean \pm SD \\
\hline 19 & $\mathrm{n}=53$ & $154 \pm 1.94$ & $22 \pm 1.8$ & $54 \pm 12$ \\
\hline 20 & $\mathrm{n}=123$ & $157 \pm 3.38$ & $22 \pm 1$ & $53 \pm 10$ \\
\hline 21 & $\mathrm{n}=200$ & $157.5 \pm 2.6$ & $24 \pm 4.6$ & $52 \pm 11$ \\
\hline 22 & $\mathrm{n}=156$ & $150 \pm 1.76$ & $23.6 \pm 2.9$ & $55 \pm 10$ \\
\hline 23 & $\mathrm{n}=201$ & $152 \pm 2.9$ & $26 \pm 2.3$ & $56 \pm 4$ \\
\hline 24 & $\mathrm{n}=71$ & $157 \pm 1.98$ & $26 \pm 0.25$ & $57 \pm 5$ \\
\hline
\end{tabular}

\begin{tabular}{|c|c|}
\hline Postural problem & Percentage \\
\hline Swayback & 2.9 \\
\hline Lumbar lordosis & 2.4 \\
\hline Thoracic kyphosis & 1.9 \\
\hline Forward head & 11.4 \\
\hline Rounded shoulder & 8.3 \\
\hline Pronated foot & 5.5 \\
\hline
\end{tabular}

\section{Discussion}

Normal body posture is a relative term. Undoubtedly, it exerts a great effect on quality of life in relation to the statics and dynamics of human functioning. Type of posture depends on many factors such as race, somatic type, gender, and age. Poor posture is manifested by change in body shape without any subjective complaints, such as pain, and can be evaluated by various methods. These conditions usually continue without proper attention.

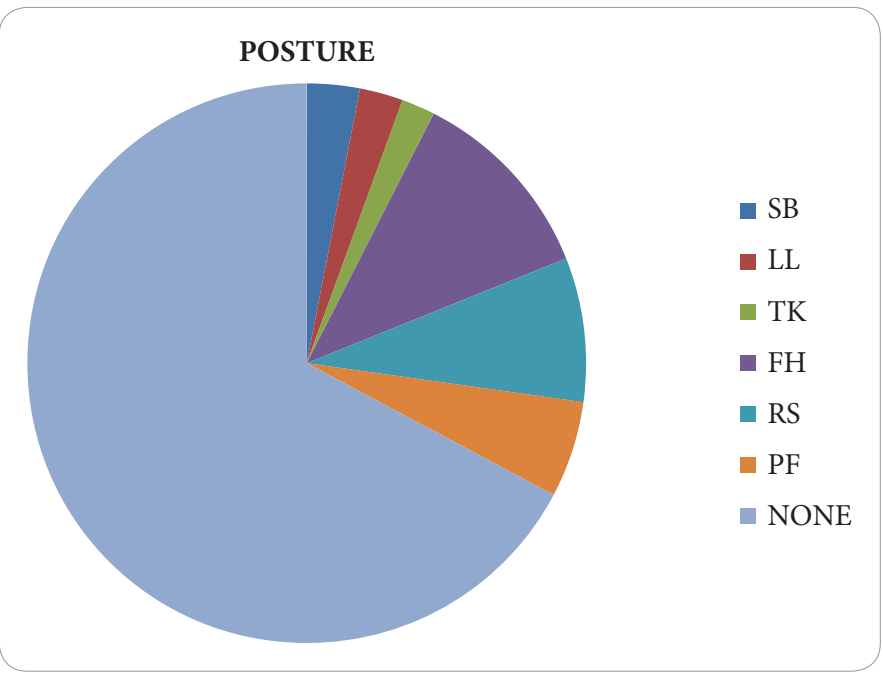

SB, Swayback; LL, Lumbar lordosis; TK, Thoracic kyphosis FH, forward head; RS, Rounded shoulder; PF, Pronated foot.

In this study, we analyzed the prevalence of postural abnormalities in 804 female college students. Posture of the participants was analyzed from the photographs in both the sagittal and frontal planes. A statistically significant relationship was found between habit and postural defect. Back pain was more frequent in female college students with postural defect. This result coincides with the result of Mörl et al. [7], which states that postural defect probably predisposes to the feeling of discomfort and back pain in an adolescent with a sedentary style of work.

Older female subjects show higher incidence of postural misalignments, such as forward head and rounded shoulder. Female subjects with higher BMI had pronated foot. Many of the participants complained of pain only during prolonged sitting and leisure activities. The most common malalignment among female college students was found to be rounded shoulder, forward head, and pronated foot.

\section{Conclusion}

This study shows higher prevalence of postural problems among female college students that needs to be mitigated to prevent further problems. There is a need for educating college female students concerning postural defects, risks resulting from these defects, and selfawareness of their health. There exists a relationship between physical activity and postural defect among female college students.

\section{References}

1. Bogdanović Z, Marković Ž (2009) Relationship between morphological characteristic and postural status of elementary school students. J Sports Sci 2: 102-106.

2. Brianezi L, Cajazeiro DC, Maifrino LBM (2011) Prevalence of postural deviations in school of education and professional practice of physical education. J Morphol Sci 28: 35-36.

3. Minoo D (2013) Prevalence and causes of postural deformities in upper and lower extremities among 9-18 years old school female in Golestan province. Euro J Exp Biol 3(6): 115-121.

4. Latalski M, Bylina J, Fatyga M, Repko M, Filipovic M, et al. (2013) Risk factors of postural defects in children at school age. Ann Agric Environ Med 20: 583-587.

5. Kratenová J, Zejglicová K, Malý M, Filipová V (2007) Prevalence and risk factors of poor posture in school children in the Czech Republic. J Sch Health 77: 131-137. 
Citation: Kiruthika S, Rekha K, Preethy G, Abraham M (2018) Prevalence of Postural Dysfunction among Female College Students—A Qualitative Analysis. Biol Med (Aligarh) 10: 421. DOI: 10.4172/0974-8369.1000421

Page 3 of 3

6. Filipova V (2002) Prevention and compensation of poor posture in younger schoo children in the elementary school regime [PhD thesis in Czech]. Brandy's nad Labem, Czech Republic: Nursing Secondary School and College Mills.

7. Mörl F, Bradl I (2012) Lumbar posture and muscular activity while sitting during office work. J Electromyogr Kinesiol 23(2): 362-368.

8. Sygit K, Kołłątaj W, Goździewska M, Sygit M, Kołłątaj B, et al. (2012) Lifestyle as an important factor in control of overweight and obesity among schoolchildren from the rural environment. Ann Agric Environ Med 19(3): 557-561.
9. Suliburska J, Bogdański P, Pupek-Musialik D, Głod-Nawrocka M, Krauss H, et al. (2012) Analysis of lifestyle of young adults in the rural and urban areas Ann Agric Environ Med 19(1): 135-139.

10. Seefeldt V, Malina RM, Clark MA (2002) Factors affecting levels of physical activity in adults. Sports Med 32(3): 143-168.

11. May S (2011) High frequency of McKenzie's postural syndrome in young population of non-care seeking individuals. J Man Manip Ther 19(1): 48-54. 